\title{
1738 Years of Mongolian Temperature Variability Inferred from a Tree-Ring Width Chronology of Siberian Pine
}

\author{
Rosanne D'Arrigo ${ }^{1}$, Gordon Jacoby ${ }^{1}$, David Frank ${ }^{1}$, Neil Pederson ${ }^{1}$, Edward Cook ${ }^{1}$, \\ Brendan Buckley ${ }^{1}$, Baatarbileg Nachin ${ }^{2}$, R. Mijiddorj ${ }^{3}$ and Chultamiin Dugarjav ${ }^{4}$
}

\begin{abstract}
AD 262-1999) of temperature variability are inferred from tree-ring widths of Siberian pine at Solongotyn Davaa (Sol Dav), a timberline $(2420 \mathrm{~m})$ site in Mongolia. This chronology can account for $33 \%$ of the temperature variance from 1882-1993. The warmest conditions over the past millennium are during the 20th century. The 1999 ring width has the highest index value over the past millennium. Both warmer and colder intervals are inferred during the "Medieval Warm Epoch". The most severe cold occurred in the 19th century. Unusual cold and frost in AD 536-545 coincide with extremes in other proxies and historical accounts, confirming a widespread, catastrophic event. Trends resemble those of other Eurasian paleoseries, and hemispheric-scale reconstructions over the past millennium. More chronologies such as Sol Dav are essential to improve coverage in the uncertain earlier centuries of these reconstructions and their estimates of natural variability relative to recent anthropogenic change.
\end{abstract}

\section{Introduction}

The causes and mechanisms of decadal to century-scale Holocene climate variability are still not well understood, necessitating the generation of high-resolution proxy records of climate spanning recent centuries to millennia [e.g., Cook et al., 1991]. Some of these data have been compiled into networks for development of large-scale, even global, temperature reconstructions covering the past several centuries [Jacoby and D'Arrigo, 1989; Bradley and Jones, 1993; D'Arrigo and Jacoby, 1993; Overpeck et al., 1997; Mann et al., 1998] and up to the last millennium [Mann et al., 1999]. Prior to ca. 1600 , however, there are increasing errors in the estimated trends [Mann et al., 1999]. These uncertainties result largely from the scarcity of millennial records, particularly for remote regions of Eurasia.

To help meet the need for millennial time series [Briffa and Osborn, 1999], we have produced an extended tree-ring width chronology of Siberian pine (Pinus sibirica Du Tour) at Solongotyn Davaa (Sol Dav), an elevational timberline site in the Tarvagatay Mountains of Mongolia (Figure 1). The previous record of Siberian pine for this site (formerly Tar Pass), based only on wood from living trees, extended from

\footnotetext{
Tree-Ring Lab, Lamont-Doherty Earth Observatory, Palisades, NY 10964 USA. (email druidrd@1deo.columbia.edu)

${ }^{2}$ National University of Mongolia, Ulaanbaatar, Mongolia; ${ }^{3}$ Hydrometeorological Research Institute, Ulaanbaatar, Mongolia; ${ }^{4}$ Institute of Botany, Ulaanbaatar, Mongolia
}

Copyright 2001 by the American Geophysical Union.

Paper number 2000GL011845

0094-8276/01/2000GL011845\$0S.00
AD 1465-1994 [Jacoby et al., 1996]. Taking into consideration ecological site conditions outlined in Jacoby et al. [1996], as well as comparisons with instrumental and proxy climate data (see below), tree growth at this location appears to be primarily limited by temperature.

\section{Sol Dav Millennial Length Tree-Ring Width Chronology}

Additional sampling at Sol Dav has now yielded abundant relict wood material (and updated living tree records through 1999). The ring-width measurements from the relict collections were cross-dated with each other and with living tree data by visual alignment of ring characteristics and computer-assisted dating techniques [Stokes and Smiley, 1968; Holmes, 1983]. Conservative detrending employed negative exponential or straight line curve fits, or stiff splines to remove age-related growth trends [Fritts, 1976; Cook, 1985: Cook and Kairiukstis, 1990]. Splines (with a 50\% frequency-response cutoff) between 300 and 700 years were used in 10/99 cases. During standardization [Cook, 1985], a power transform technique was used to stabilize the variance and residuals from the fitted curves were computed to avoid potential bias in calculation of indices [Cook and Peters, 1997]. The final chronology (Figure 2) consists of 38 radii from 19 living trees and 61 radii from 32 relict trees.

The expressed population signal (EPS) is one criterion used to evaluate the reliability of tree-ring chronologies in a quantitative sense, with a value exceeding 0.85 considered acceptable by some researchers [Wigley et al., 1984; Cook and Kairiukstis, 1990]. The EPS, which partly depends on sample size, measures how well the finite chronology compares with a theoretical infinite population. Another useful criterion is the RBAR, or average correlation between tree-ring series. RBAR is independent of sample size and is an indication of common variance [Cook and Kairiukstis, 1990]. Prior to about AD 850, the value of the EPS and

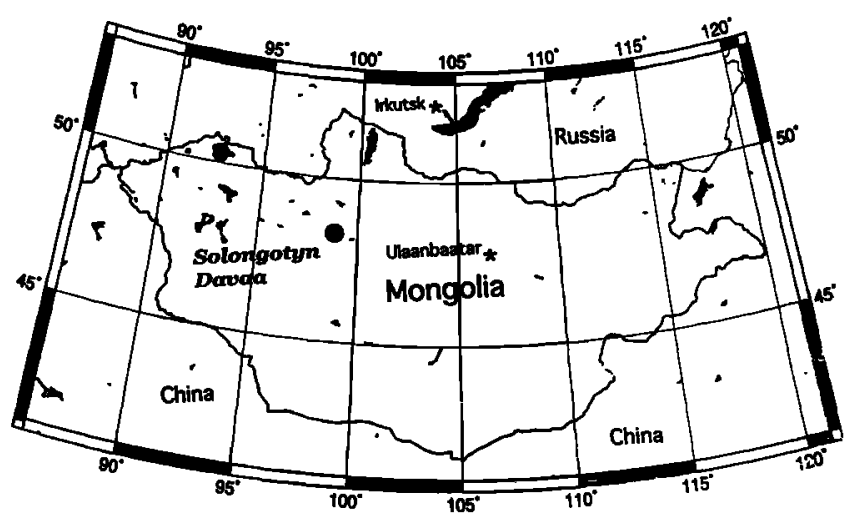

Figure 1. Map of Mongolia showing Sol Dav tree-ring site (dot) and other locations mentioned in text. 

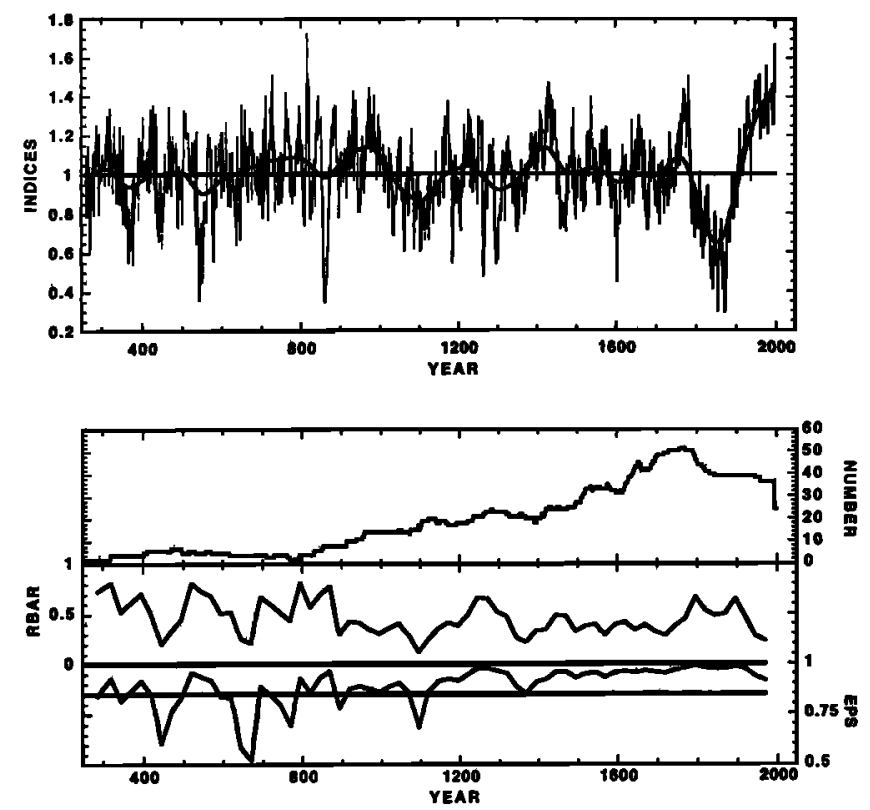

Figure 2. Top, Sol Dav record from AD 262-1999. Smoothed curve is 150-year spline; horizontal line shows long-term mean. Lower graphs: sample size, running RBAR and EPS. RBAR and EPS used moving 50-yr windows, lagged $25 \mathrm{yr}$.

reliability of the RBAR decrease as sample size diminishes. Also, RBAR values early in the record may be somewhat inflated due to a higher percentage of correlations being computed from within the same trees (Figure 2). We thus consider this chronology to be most reliable over the past 1150 years (AD 850-1999). However, the EPS remains $>0.85$ for some intervals prior to $\mathrm{AD} 850$, indicating that there is still reasonable agreement with the population chronology and useful climatic information. The lower EPS and RBAR values ca. 1100 (Figure 2) seem to result from suppressed growth during this cool period in more mature trees and somewhat erratic juvenile growth in trees entering the chronology about this time. Since resolution of low-frequency information may be limited by the length of individual segments [Cook et al., 1985], care was taken to balance sample size with segment length in chronology development. Average segment length is 341 years, with a standard deviation of 110 years.

\section{Climate Analyses}

There are very few meteorological stations in the general vicinity of the Sol Dav site, and these are only several decades in length [Jacoby et al, 1996; Jacoby et al., 1999]. At six hundred kilometers distance and at much lower elevation (470 $\mathrm{m}$ ), the station record for Irkutsk, Russia (Figure 1) is the longest such series available for the vicinity of Sol Dav. The Irkutsk annual temperature record shows an overall steady rise over its length with the highest levels in the $1990 \mathrm{~s}$, as in the annual Northern Hemisphere average. Gridded temperatures overlapping the Sol Dav site $\left(45-50^{\circ} \mathrm{N}, 95-\right.$ $100^{\circ} \mathrm{E}$; P. Jones, pers. comm.) are almost entirely based on the Irkutsk record. As in Jacoby et al. [1996], the strongest correlations were found between annual ring-width indices and prior August through current July temperatures from 1882-1993 $(r=0.44)$. Averaged over four years (using tree growth in year $t$ to estimate temperature averaged over years $t-3$ to $t$ ), this model accounts for $33 \%$ of the variance, adjusted for degrees of freedom. This finding reflects the fact that tree physiology can integrate response to an impulse several years after the event [Fritts, 1976; Kramer and Kozlowski, 1979; Cook, 1985]. Despite this climate/growth relationship we do not consider this model sufficient for development of a verifiable reconstruction [ Fritts 1976].

The Sol Dav chronology allows the 20th century warming to be placed in context with the past 1738 years. Focusing on the past millennium, the highest 20,50 and 100 -year growth intervals all fall within the 20th century (1980-99, 1950-99 and 1900-99). The 20-year interval from 1942-1961 is the next highest on record; it approximates the highest growth level found in the shorter version of this series [Jacoby et al., 1996]. Living trees were cored in late August of 1999, when perhaps a few weeks of the growing season still remained, evidenced by various stages of latewood formation. Despite not being complete, the 1999 value is 1.678 , over 3 standard deviations above the long-term mean of 1.0. This is the highest value in the past thousand years, and the second highest in the entire series. Further, eight of the ten highest growth years in the past millennium are since 1950.

Other notable periods of comparable warmth are inferred around $A D 800$ (the year 816 , the highest in the entire record, has a value of 1.729), in the early $1400 \mathrm{~s}$, and at the end of the 18 th century (Figure 2). The two earlier intervals bracket the "Medieval Warm Epoch" (MWE), interpreted to have occurred sometime within the 9th-14th centuries [Lamb, 1965]. However, there are also periods of inferred cold (e.g., around 1100), supporting evidence that the MWE was not a global phenomenon of synchronous, sustained warmth [e.g., Hughes and Diaz, 1994; Overpeck et al., 1997]. The MWE may thus not be a valid analog for the global warming of the 20 th century and its association with anthropogenic influences.

The most pronounced, sustained cooling at Sol Dav is in the 1800s, during the "Little Ice Age" [Grove, 1988] (Figure 2). The lowest 20,50 and 100 -yr intervals over the past millennium are all in the 19th century. Although there is considerable variation in the phasing of relative cold and warmth during the Little Ice Age, depending on location, the early to middle 1800 s may be the most spatially coherent period of Little Ice Age cooling within the Northern Hemisphere [Grove, 1988]. Solar effects, volcanism, and atmosphere-ocean dynamics may all be possible causes for the cold conditions at this time [e.g., Jones et al., 1996].

Samples were inspected for frost damage [LaMarche and Hirschboeck, 1984] and wood breakage which can signify unusual high-frequency events (e.g., cold surges, related to the East Asian monsoon; Zhang et al., 1996) in the continental Mongolian landscape. One of the most notable frost ring occurrences is in $\mathrm{AD} 536$ [D'Arrigo et al., in press, a], which shows visible frost damage in the latewood and signals the onset of an unusually cold decade (AD 536-545). The mean ring-width index for this decade is 0.670 , with a minimum value of 0.37 in AD 543 (Figure 2).

There are other indications of unusual conditions at this time. Chinese historical records document dim sun, summer frosts, and famine in AD 536 [Baillie, 1999]. AD 540 is one of the narrowest rings in the first millennium $A D$ in Irish oaks [Baillie, 1999], and AD 536 is the second coldest summer in 1500 years in a tree-ring temperature record from Fennoscandia [Briffa et al., 1992]. There is also reduced growth from AD 536-545 in other European chronologies 


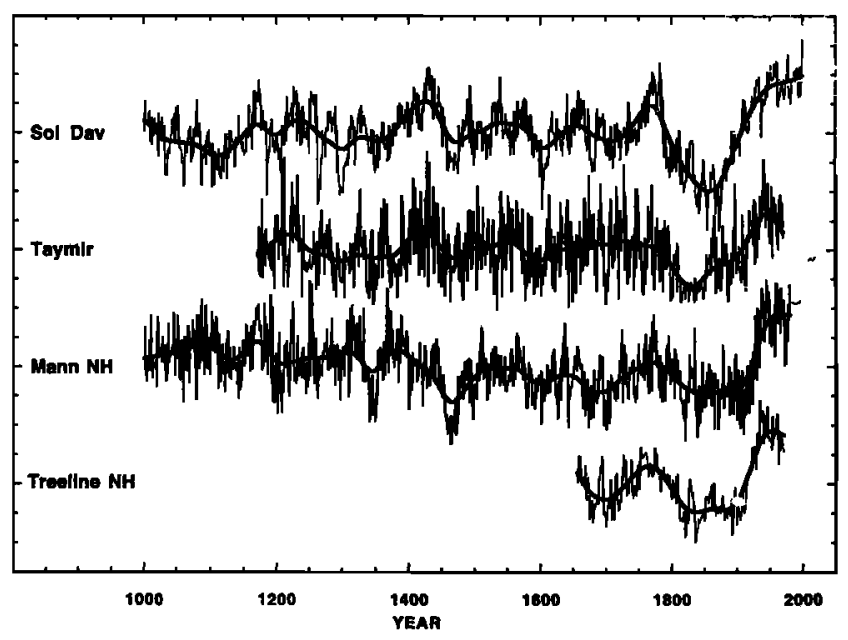

Figure 3. Sol Dav chronology and three other series: a chronology from Taymir, Siberia [Jacoby et al., 2000]; and two Northern Hemisphere temperature reconstructions, one based on proxy and other data [Mann et al., 1999]; the other on 21 tree-ring series (modified from Jacoby and D'Arrigo, 1989). Annual correlations with Sol Dav: Taymir, $\mathrm{r}=0.25$, 1170-1970; Mann, $r=0.37,1000-1980$; treeline reconstruction, $r=0.74,1655-1970$. Time series smoothed with 80-year spline to emphasize low frequencies. Correlations between the smoothed Sol Dav record and these series are: $r=0.87$ for Taymir, $r=0.53$ for Mann, $r=0.93$ for treeline reconstruction. Units are dimensionless indices.

[Baillie, 1999]. A temperature-sensitive 2,000-year North American tree-ring record shows AD 535, 536 and 541 to be the second, third and fourth coldest years [Scuderi, 1993]. Whether this highly unusual, spatially widespread event was related to a volcanic eruption or other phenomenon must await more definitive information [Baillie, 1999].

\section{Comparison with other Paleoclimatic Time Series}

Our results thus suggest that the coldest and warmest conditions in northern Mongolia over the past millennium occurred in the 19th and 20th centuries, respectively. Similarly, tree-ring reconstructions for Eurasia show 19th century cooling, and 20th century warming, for the Polar Urals [Briffa et al., 1995], Yakutia [Hughes et al., 1999], and the Taymir Peninsula, Russia [Jacoby et al., 2000]. There is also correspondence between Sol Dav and larger-scale temperature reconstructions [e.g., Overpeck et al., 1997; Mann et al., 1999]. For example, Sol Dav correlates annually with the Mann et al. [1999] multiproxy hemispheric reconstruction at $\mathrm{r}=0.37$ over the past thousand years.

Smoothed decadal and longer fluctuations for Sol Dav are compared (Figure 3) with the Taymir chronology [Jacoby et al., 2000]; and two hemispheric temperature reconstructions. One is that of Mann et al. [1999]; the other is a 300-yr reconstruction based solely on northern tree-ring data [modified from Jacoby and D'Arrigo, 1989; D'Arrigo et al., 1999]. There is excellent correspondence over the past several centuries among these four smoothed records, which all reflect relative warmth in the 1700 s, cold 1800 s and warmth in the 20th century. There is also agreement in showing relative warmth in the early 1400 s and cooling in the middle to later $1400 \mathrm{~s}$. Further back in time, although there are similarities between the Sol Dav and Taymir series, there is less agreement with the Mann et al. [1999] reconstruction.

Some recent treeline studies [e.g., Jacoby and D'Arrigo, 1995; Briffa et al., 1998] suggest a loss in temperature sensitivity in recent decades. Recent growth decreases have been attributed to drought stress [Jacoby and D'Arrigo, 1995] or other adverse influences [Vaganov et al., 1999]. There appears to be no such shift in response at Sol Dav, indicating the trees' continued response to temperature.

\section{Conclusions}

It should not be surprising to see similar trends among widely-separated temperature-sensitive tree-ring series for the Northern Hemisphere when the major forcings of volcanism, solar variations and trace gases are considered. The 20th century warming, and 19th century cooling (Figures 2-3) are the most extreme and coherent trends common to the northern sites we have studied [Jacoby and D'Arrigo, 1989; D'Arrigo and Jacoby, 1993; D'Arrigo et al., 1999, in press, b; and herein]. These recent, more coherent trends suggest the possibility of stronger common forcings becoming more dominant over regional variations, in particular the increasing trace gases in the 20th century [Jones et al., 1996]. Less coherent fluctuations among the records back in time may signify more regional effects, and also the need for additional coverage for a more accurate perspective of climatic change. One of the most promising resources is relict and subfossil wood, which can be abundant even where old trees are few or lacking, and which can extend many centuries longer than living trees. This is particularly the case in cold locations (e.g., Mongolia) where there can be excellent preservation.

Future studies will determine whether the trees at sites like Sol Dav will retain their sensitivity if recent warming continues. Development of additional millennial records will fill remaining gaps in spatial and temporal coverage of proxy data in large-scale temperature reconstructions, and in so doing will decrease the uncertainty in our understanding of natural and anthropogenic climatic change.

On a historical note, the Mongolian leader Chinggis Khaan expanded his empire westward in the early-middle 1200s [Hoang, 1990]. He began his campaign to the west (Eurasia, Middle East) in 1219, taking Merv (Central Asia, east of the Caspian Sea) in 1221, and reaching north of the Black Sea in 1223. Chinggis Khaan died in 1227; however the Mongols persisted, reaching Moscow in 1238, Kiev in 1240, and Budapest in 1241 [Hoang, 1990]. At Sol Dav, the earlymiddle 13 th century is an extended warm period which may have facilitated the travels of the Khaan and his followers.

Acknowledgments. This research was funded by the National Science Foundation. We thank the Mongolian Ministry for Nature \& Environment, Mongolian Institute of Biological Sciences, Mongolian Hydrometeorological Institute, and National University of Mongolia. LDEO No. 6121 .

\section{References}

Baillie, M., Exodus to Arthur. Catastrophic Encounters with Comets, Batsford, London, 1999.

Bradley, R., and P. Jones, "Little Ice Age" summer temperatures: their nature and relevance to recent global warming trends, The Holocene, 3, 367-376, 1993. 
Briffa, K., P. Jones, T. Bartholin, D. Eckstein, F. Schweingruber, W. Karlen, P. Zetterberg, and M. Eronen, Fennoscandian summers from $\mathrm{AD} 500$ : temperature changes on short and long time scales, Climate Dynamics, 7, 111-119, 1992.

Briffa, K, P. Jones, F. Schweingruber, S. Shiyatov, and E. Cook, Unusual twentieth century summer warmth in a 1000-year temperature record from Siberia, Nature, 393, 450-455, 1995.

Briffa, K., and T. Osborn, Climate warming: seeing the wood from the trees, Science, 284, 926-927, 1999.

Briffa, K., F. Schweingruber, P. Jones, and T. Osborn, Reduced sensitivity of recent tree growth to temperature at high northern latitudes, Nature, 391, 678-682, 1998.

Cook, E., A time series analysis approach to tree-ring standardization, Ph.D. thesis, Univ. AZ, 1985.

Cook, E., and L. Kairiukstis, Methods of Dendrochronologv, Kluwer, Dordrecht, 1990.

Cook, E., and K. Peters, Unbiased tree-ring standardization for studies of climatic and envirommental change, The Holocene, 7, 361-370, 1997.

Cook, E., K. Briffa, D. Meko, D. Graybill, and G. Funkhouser, The "segment length curse" in long tree-ring chronology development for paleoclimatic studies, The Holocene, 5, 229. $237,1995$.

Cook, E., T. Bird, M. Peterson, M. Barbetti, B. Buckley, R. D'Arrigo, R. Francey, and P. Tans, A 1089-year temperature record for Tasmania inferred from tree rings of subalpine huon pine, Science, 253, 1266-1268, 1991

D'Arrigo, R., and G. Jacoby, Secular trends in high northem latitude temperature reconstructions based on tree rings, Climatic Change, 25, 163-177, 1993.

D'Arrigo, R., G. Jacoby, M. Free, and A. Robock, Northern Hemisphere temperature variability for the past three centuries: tree-ring and model estimates, Clinatic Change 42, 663-675, 1999.

D'Arrigo, R., D. Frank, G. Jacoby, N. Pederson, Spatial response to major volcanic events in or about $\mathrm{AD} 536,934$ and 1258: frost rings and other dendrochronological evidence from Mongolia and northern Siberia, in press, a, Climatic Change.

D'Arrigo, R., G. Jacoby, N. Pederson, D. Frank, B. Buckley, B. Nachin, R. Mijiddorj, and C. Dugarjav, Mongolian tree rings, temperature sensitivity and reconstructions of Northern Hemisphere temperature, in press, $\mathrm{b}$, The Holocene.

Fritts, H., Tree Rings and Climate, Academic Press, NY, 1976.

Grove, J., The Little Ice Age, Methuen, London, 1988.

Hoang, M., Genghis Khan, Saqi Books, London, 1990.

Holmes, R., Computer-assisted quality control in tree-ring dating and measurement, Tree-Ring Bull., 43, 69-78, 1983.

Hughes, M., and H. Diaz, Was there a Medieval Warm Period, and if so, where and when? Climatic Change, 26, 109-142, 1994.

Hughes, M., E. Vaganov, S. Shiyatov, R. Touchan, and G. Funkhouser, Twentieth century summer warmth in northern Yakutia in a 600-year context, The Holocene, 9, 629-634, 1999.

Jacoby, G., and R. D'Arrigo, Reconstructed Northern Hemisphere annual temperature since 1671 based on high latitude tree-ring data from North America, Climatic Change, 14, 39-59, 1989.
Jacoby, G., and R. D'Arrigo, Tree-ring width and density evidence of climatic and potential forest change in Alaska, Glob. Biogeochem. Cycles, 9, 227-234, 1995.

Jacoby, G., R. D'Arrigo, and Ts. Davaajamts, Mongolian tree rings and 20th century warming, Science, 273, 771-773, 1996.

Jacoby, G. , R. D'Arrigo, N. Pederson, B. Buckley, C. Dugarjav, and R. Mijiddorj, Temperature and precipitation in Mongolia based on dendroclimatic investigations, IAWA Joumal, 20, 339-350, 1999.

Jacoby, G., N. Lovelius, O. Shumilov, O. Raspopov, J. Kurbinov, and D. Frank, Long-term temperature trends and tree growth in the Taymir region of northern Siberia, Quat. Res., 53, 312$318,2000$.

Jones, P., R. Bradley, and J. Jouzel, (eds), Clinatic Variations and Forcing Mechanisms of the last 2000 Years, NATO ASI Series, Series I, Global Environmental Change, Vol. 41, Springer, NY, 1996.

Kramer, P., and T. Kozlowski, Physiology of Woody Plants, Academic Press, NY, 1979.

LaMarche, V. Jr., and K. Hirschboeck, Frost rings in trees as records of major volcanic enuptions, Nature, 307, 121-126, 1984.

Lamb, H., The early Medieval Warm Epoch and its sequel, Palaeo-3, l, 13-37, 1965.

Mann, M., R. Bradley, and M. Hughes, Global-scale temperature patterns and climate forcing over the past six centuries, Nature, 392, 779-787, 1998.

Mann, M., R. Bradley, and M. Hughes, Northern Hemisphere temperatures during the past inillennium: inferences, uncertainties, and limitations, Geophys. Res. Lett., 26, 759762, 1999.

Overpeck, J., K. Hughen, D. Hardy, R. Bradley, R. Case, M. Douglas, B. Finney, K. Gajewski, G. Jacoby, A. Jennings, S. Lamoureux, A. Lasca, G. MacDonald, J. Moore, M. Retelle, S. Smith, A. Wolfe, and G. Zielinski, Arctic environmental change of the last four centuries, Science, 278, 1251-1256, 1997.

Scuderi, L., A 2000-year tree-ring record of annual temperatures in the Sierra Nevada Mountains, Science, 259, 1433-1436, 1993.

Stokes, M., and T. Smiley, An Introduction to Tree-Ring Dating, Univ. Chic. Press, Chicago, 1968.

Vaganov, E., M. Hughes, A. Kirdyanov, F. Schweingruber, and P. Silkin, Influence of snowfall and melt timing on tree growth in subarctic Eurasia, Nature, 400, 149-151, 1999.

Wigley, T., K. Briffa, and P. Jones, On the average value of correlated time series, with applications in dendroclimatology and hydrometeorology, J. Clim. Appl. Met., 23, 201-213, 1984.

Zhang, Y., K. Sperber, and J. Boyle, Climatology of East Asian winter monsoon and cold surges: results from 1979-1995 NC EP/NCAR reanalysis, PCMDI Report No. 38, Program for Climate Model Diagnosis \& Intercompar., LLNL, CA, 1996.

(Received June 5, 2000; revised October 31, 2000; accepted November 1, 2000.) 